\title{
A Clinical Study on Gallstones in Bolivia
}

\author{
Motonobu Sugimoto, MD, Tohru Abei, MD and Haruo Kameda, MD*
}

\begin{abstract}
To clarify the prevalence of gallstone disease in Bolivia, all the X-ray films of the biliary system in a total of 656 cases taken during 10 months in La Paz were checked. Gallstones were found in 103 cases $(15.7 \%)$. The ratio of male to female was $1: 1.9$. Cholecystolithiasis comprised $76.7 \%$ of them, while choledocholithiasis was rare. The analysis of gallstones removed surgically by an infrared absorption spectroscopy revealed that cholesterol was main constituent of stones in 62 cases (93.9\%) out of 66 cases.
\end{abstract} gallstone

Key Words: Gallstone, Cholecysto-cholangiography, Infrared spectroscopic analysis for

The purpose of this study is to elucidate the clinical features of biliary tract diseases, especially those related to gallstones in La Paz, Bolivia, where gastroenterological diseases are incriminated as the most frequent ones. The incidence of gallstones and their composition were studied to evaluate an ethnic and etiologic factors in this country, comparing to other countries including Japan.

\section{SUBJECTS AND METHODS}

During 10 months (May 1979 - February 1980), 5173 patients visited the Institute of Gastroenterology in La Paz. A total number of 702 radiological examinations of the biliary system were performed in 656 patients, including 625 of indirect cholangiography (555 of oral cholecystography and 70 of intravenous or drip infusion cholangiography (DIC)), 45 of endoscopic retrograde cholangiography (ERC) and 32 of percutaneous transhepatic cholangiography (PTC).

Following findings were evaluated on the X-ray films; (1) degrees of concentration of the contrast medium and contraction of the gallbladder in oral cholecystography, (2) relationship between concentration and contraction of the gallbladder in the gallstone cases, (3) opacified area of the biliary tree in intravenous cholangiography, DIC, ERC and PTC, (4) location of gallstones, (5) other abnormalities than gallstones observed in direct cholangiography (ERG and PTC).

The constituents of gallstones obtained surgically in 66 cases were analyzed by an infrared absorption spectroscopy.

\section{RESULTS}

\section{Cholecysto-cholangiography}

In 555 cases with oral cholecystography, 269 (48.5\%) were normal, whereas other cases had some abnormalities including poor dye concentration, poor contraction and deformity of the gallbladder. Gallstones were observed in 67 (12.1\%), with a clear predominance of gallbladder stones (Table 1). Of the 67 gallstone cases, $23(34.3 \%)$ showed normal dye concentration and contraction of the gallbladder (Table 2).

Out of 70 cases of intravenous cholangiography and DIC, only $13(18.6 \%)$ were normal and others showed some abnormalities. Gallstones were observed in 19 (27.1\%); 13 in the gallbladder, 5 in the common bile duct and 1 in both (Table 3). Although in 7 (36.8\%) of 19 cases with gallstones both the gallbladder and common bile duct were clearly opacified, these were not always visualized

From the Second Department of Internal Medicine, Toho University School of Medicine and the *First Department of Internal Medicine, Tokyo, Jikei-kai Medical College.

Received for publication July 19, 1982.

Request Reprints to: Motonobu Sugimoto MD. The Second Department of Internal Medicine, Toho University School of Medicine, 11-1, 6-chome, Omori-nishi, Ota-ku, Tokyo 143, Japan. 
Table 1. Findings in oral cholecystography in 555 cases

\begin{tabular}{|c|c|c|c|}
\hline & & No. of ce & $\%)$ \\
\hline \multicolumn{2}{|l|}{ Normal } & 269 & $(48.5)$ \\
\hline \multicolumn{4}{|l|}{ Abnormal } \\
\hline \multirow[t]{2}{*}{ Gallstone } & Gallbladder & 66 & $(11.9)$ \\
\hline & Gallbladder \& bile duct & 1 & $(0.2)$ \\
\hline \multicolumn{4}{|c|}{$\begin{array}{l}\text { Other (Deformity of gallbladder, } \\
\text { concentration \& contraction }\end{array}$} \\
\hline \multicolumn{2}{|c|}{ abnormalities) } & 219 & $(39.5)$ \\
\hline
\end{tabular}

Table 2. Relation between concentration and contraction in oral cholecystography in gallstone cases (67 cases)

\begin{tabular}{ccccccc}
\hline \hline & \multicolumn{5}{c}{ Contraction } \\
\cline { 2 - 6 } Concen- \\
\cline { 2 - 6 } & + & \pm & - & $\begin{array}{l}\text { Not ex- } \\
\text { amined }\end{array}$ & Total \\
\hline+ & $23(34.3)$ & $19(28.4)$ & $6(9.0)$ & $1(1.5)$ & $49(73.1)$ \\
\pm & $4(6.0)$ & $2(3.0)$ & $5(7.5)$ & $4(6.0)$ & $15(22.4)$ \\
- & 0 & 0 & 0 & $3(4.5)$ & $3(4.5)$ \\
\hline Total & $27(40.3)$ & $21(31.3)$ & $11(16.4)$ & $8(11.4)$ & $67(100)$ \\
\hline
\end{tabular}

Table 3. Findings in intravenous cholangiography in 70 cases

\begin{tabular}{llrr}
\hline \hline & & No. of case $\%)$ \\
\hline $\begin{array}{l}\text { Normal } \\
\text { Abnormal } \\
\text { Gallstone }\end{array}$ & Gallbladder & 13 & $(18.6)$ \\
& Gallbladder \& bile duct & 13 & $(18.6)$ \\
& Bile duct & 5 & $(1.4)$ \\
Others & & 38 & $(54.3)$ \\
\hline
\end{tabular}

in the remaining cases, in which tomography was needed to clarify the gallstones.

In 45 cases of ERC, 9 were normal (20.0\%), while gallstones were detected in 12 (26.7\%); 3 in the gallbladder, 6 in the bile duct and 3 in both, and cancer was diagnosed in 2 cases. Although 13 cases (28.9\%) were failures using this technique, valuable information was obtained in successful ones. In 32 cases of PTC, no normal diagnosis was made, and gallstones were observed in $12(37.5 \%) ; 3$ in the gallbladder, 3 in the bile duct and 6 in both, and cancer was found in 9 cases, 2 of which gallstones were simultaneously present. It was unsuccessful only in 6 cases $(\mathbf{1 8 . 8 \%})$, the rate being lower than in ERC.

Final diagnoses of the patients who received ERG and/or PTC are noted (Table 4). There were 23 cases of gallstones, including 8 of bile duct 
Table 4. Final diagnoses of the direct cholangiography cases

1) Gallstone

\begin{tabular}{ll} 
Gallbladder & 6 cases \\
Gallbladder and bile duct & 9 \\
Bile duct & $8(8)^{*}$ \\
\hline
\end{tabular}

2) Cancer

Liver 2

Gallbladder

6

Pancreas

2

Papilla

1

3) Others

$\begin{array}{ll}\text { Iatrogenic choledochal stenosis } & 5(5)^{*} \\ \text { Biliary-digestive fistula } & 3(3)^{*} \\ \begin{array}{l}\text { Choledochal dilatation due to } \\ \text { odditis }\end{array} & 2(1) * \\ \begin{array}{l}\text { Choledochal stenosis due to } \\ \text { pancreatitis }\end{array} & 1 \\ \begin{array}{l}\text { Choledochal obstruction due to } \\ \text { penetration of duodenal ulcer }\end{array} & 1 \\ \begin{array}{l}\text { Intrahepatic gallbladder } \\ \text { Cangenital choledochus cyst }\end{array} & 1 \\ \text { Fascioliasis } & 1\end{array}$

( ) * postcholecystectomized case

stones to all of whom cholecystectomy had previously been performed. All the cases of 5 benign choledochal stenosis and 3 biliarly-digestive tract fistula were also cholecystectomized patients. Cancer was seen in 11 cases, 6 originated in the gallbladder, as shown in the table. Very rare and unexpected findings were obtained from several cases, some of which were confirmed in other examinations and/or surgical operations. 2. Statistics of gallstone cases

Statistical study on gallstones disclosed some facts as follows (Fig. 1): (1) From a total number of 656 cases receiving radiological examination, there were 103 cases with gallstones, the rate of incidence being $15.7 \%$. (2) The 3rd, 4th and 5 th decase of life were the most affected, although the incidence was already high in the 2nd one. There was a predominance in female cases, the incidence being 1.9 times higher than that of male patients. (3) Gallstones were frequently $(76.7 \%)$ located in the gallbladder and less frequently in the bile duct. 3. The compositions of gallstones
The constituents of gallstones of 66 cases were analyzed by an infrared absorption spectroscopy (Table 5). Cholesterol was the main composition of gallstones in 62 cases (93.3\%), including pure

1) Frequency of Gallstone

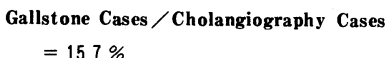

2) Relation between Age, Sex and Gallstone

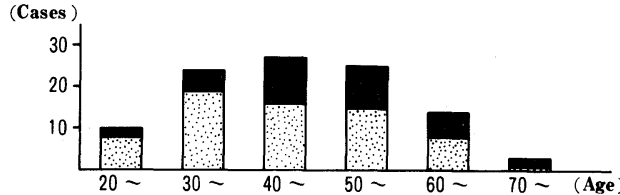

Male : Femal $=1: 1.9$

3 , Location of Gallstone

$$
\left\{\begin{array}{llc}
\text { Gallbladder } & \multicolumn{2}{c}{79 \text { Cases }(76.7 \%)} \\
\text { Gallbladder } & 11 "(10.7 \%) \\
\text { \& Bile Duct } & 11 "(12.6 ") \\
\text { Bile Duct } & 13 "
\end{array}\right.
$$

Fig. 1 Frequency, age, sex and location of gallstone (103 cases) 
Table 5. Composition of gallstones (Infrared spectroscopic analysis)

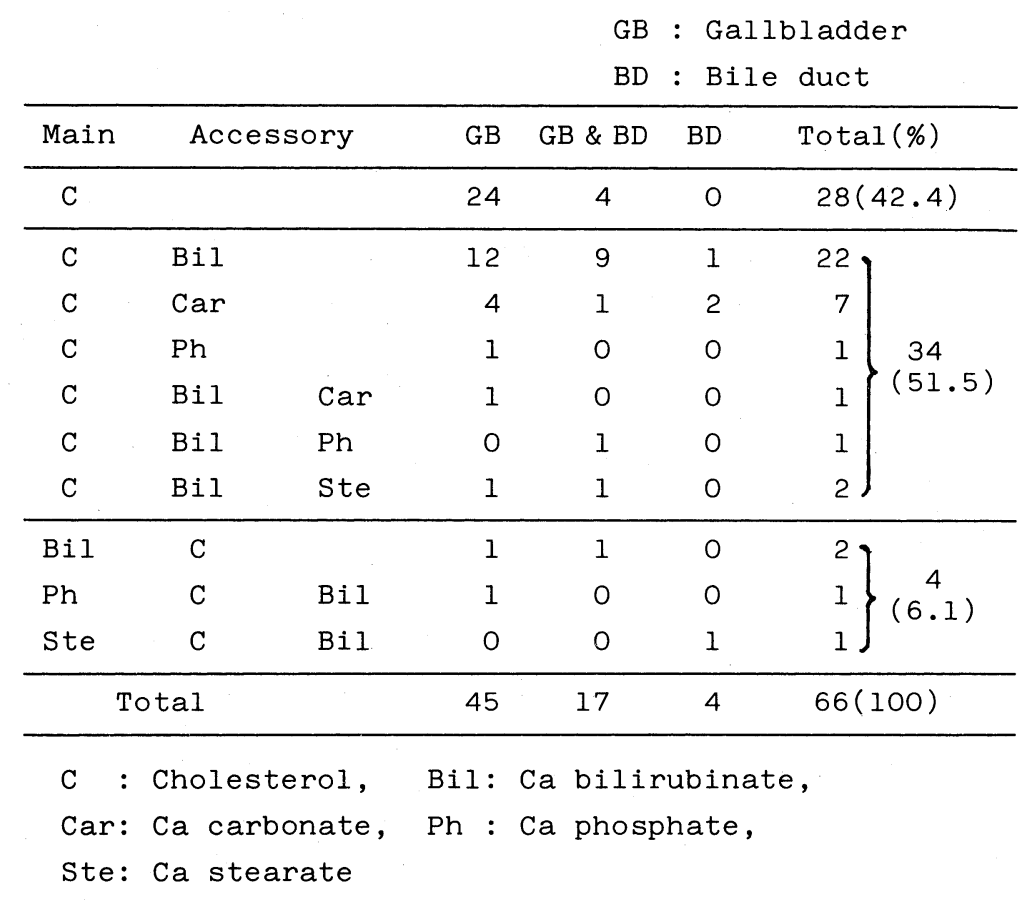

cholesterol in $28(42.2 \%)$. Other constituents as the main composition except cholesterol were only seen in $4(6.1 \%)$; calcium bilirubinate in 2 , calcium phosphate in 1 and calcium stearate in 1 .

\section{DISCUSSION}

It is well known that the incidence of gallstones differs with age, sex and race. In Europe and America, cholelithiasis is more common in females and the ratio of males to females ranges from $1: 1.8$ to $1: 6.3^{1,2)}$, while this ratio is $1: 1.4$ in Japan ${ }^{3)}$. Marked racial differences in the autopsy incidence of gallstones have already been pointed out. Various reports note an incidence of $6.9 \%$ in Caucasian male, $11.1 \%$ in Caucasian female, $1.7 \%$ in Negro male and $4.8 \%$ in Negro female ${ }^{4)}$. In Sweden it is even higher, with an average of $19.6 \%$ ( $12 \%$ of male and $27 \%$ of female $)^{5)}$. Gallstones are uncommon in Orientals, with reported incidences of $2.9 \%$ for Korea ${ }^{6)}, 3.2 \%$ for Thailand $^{7)}$ and $3.1 \%$ for Singapore ${ }^{8)}$. Kameda $(1964)^{3)}$ states that gallstones were found in $8.4 \%$ of the autopsy cases at Tokyo University Hospital in 1958.

The present study in Bolivia revealed a ratio of
1:1.9 of male to female and a incidence of $15.7 \%$. However, it is very difficult to compare this data with the statistics mentioned above, because the subjects in this study were the patients who visited our Gastroenterology Institute and were forwarded to receive radiological examinations. Although autopsy incidence should be investigated to make a comparison, it is prospected that the prevalence of gallstones in Bolivia resembles that of Europe and America.

After ultrasonography was stated to be used in La Paz in 1981, the limit of diagnostic ability in indirect cholangiography was covered and gallstone cases have been increased. Since Bolivians are mainly Indians, resembling Orientals, there may be another cause besides race for gallstone formation.

Earlier reports have commented on the prevalence of gallstones composed of bilirubin in Japan 9), although noting that Europeans and Americans ${ }^{10)}$ show a higher incidence of cholesterol stones. This difference had been attributed to a lower dietary fat intake by the Japanese, together with the prevalence of ascaris infestation $^{11)}$ in Japan. 
However, Kameda ${ }^{3)}$ demonstrated in 1964 that cholesterol stones made up $46.6 \%$ of the 812 Japanese subjects and bilirubin stones $41.5 \%$, which indicates an increase in the incidence of cholesterol stones compared with previous Japanese data.

Nagase $^{12)}$ reported from a collective review of 2144 patients in 1978 that younger Japanese adults have predominantly cholesterol stones in the gallbladder and elderly persons still frequently have bilirubin stones not only in the gallbladder but also in the bile duct. The recent increase in dietary fat intake and the decrease in biliary infection, including ascariasis, are suggested as the causes of this change.

The present study in Bolivia revealed an extraordinarily high incidence of cholesterol stones which reached 93.9\%, and no stones were composed of bilirubin as a main composition. Because it is known that Bolivians do not take a high quantity of dietary fat and that ascaris infestation reaches an incidence of $50-60 \%$, the pathogenesis of gallstone formation may be different from Japan.

It is reported in America that $70 \%$ of Pima Indian females have gallstones by age 30 , and $70 \%$ of Pima Indian males develop gallstones in later life. ${ }^{13)}$ It is also demonstrated that the hepatic bile in the patients of South-western American Indians with gallstones is highly supersaturated with cholesterol ${ }^{14}$, and that the duodenal bile in a number of Indian females with normal cholecystograms has significantly lower ratios of bile acid and lecithin to cholesterol than that of white females ${ }^{15}$.

Some abnormalities such as metabolic disorder may be present in Bolivians, too. It is recently demonstrated that the gallbladder biles from 14 Bolivian patients with gallstones contains more glycocholic and less glycodeoxycholic acid than American patients, suggesting decreased enterohepatic cycling. ${ }^{16)}$ The investigation of the lithogenicity of bile and bile acids pool size must be furthered to disclose the cause of the high prevalence of cholesterol gallstones.

ACKNOWLEDGEMENT: This work was performed in the "Instituto de Gastroenterologia Boliviano-Japones, La Paz, Bolivia".
The authors wish to thank Drs. Guido Villa-Gomez, Luis Uria and Almando Negron for their cooperation and assistance in completing this study.

\section{REFERENCES}

1) Adam R, Stranahan A: Cholecystitis and cholelithiasis: An analytical report of 1104 operative cases. Surg Gynecol Obstet 85: 776, 1947.

2) Liever MM: The incidence of gallstones and their correlation with other diseases. Ann Surg 135: 394, 1952.

3) Kameda H: Gallstone disease in Japan: A report of 812 cases. Gastroenterology 46: 109, 1964.

4) Cunningham JA, Hardenbergh FE: Comparative incidence of cholelithiasis in the negro and white races: A study of 6185 autopsies. Arch Intern Med 97: 68, 1956.

5) Martensson KM: The incidence of gallstones in Sweden: The correlation of gallstones with various diseases and pathologic changes. Arch Surg 34: 650, 1937.

6) Ludlow AI: Cholelithiasis in the Korean, Surg Gynecol Obstet 50: 51, 1930.

7) Statnimankarn $T$ : The necropsy incidence of gallstones in Thailand. Am Med Sci 240: 349, 1960.

8) Hwang WS: Cholelithiasis in Singapore: Part 1, A necropsy study. Gut 11: 141, 1970.

9) Miyake H: Statistische, klinische und chemische Studien zur Ätiologie der Gallensteine mit besonderer Berücksichtigung der japanischen und deutschen Verhältnisse. Arch Klin Chir 101: 54, 1913.

10) Gross DMB: A statistical study of cholelithiasis. J Path Bact 32: 503, 1929.

11) Maki T: Cholelithasis in the Japanese. Arch Surg 82: 599, 1961.

12) Nagase $M$, Tanimura $H$, Setoyama $M$ et al: Present features of gallstones in Japan: A collective review of 2144 cases. Am J Surg 135: 788, 1978.

13) Sampliner RE, Bennett PH, Comess LJ et al: Gallbladder disease in Pima Indians: Demonstration of high prevalence and early onset by cholecystography. N Engl J Med 283: 1358, 1970.

14) Small DM, Rapo S: Source of abnormal bile in patients with cholesterol gallstones. N Engl J Med 283: 53, 1970.

15) Thistle JL, Schoenfield LJ: Lithogenic bile among young Indian women: Lithogenic potential decreased with chenodeoxycholic acid. N Engl J Med 284: 177, 1971.

16) Levitt RE, Lafsky RD, Soloway RD et al: Differences in bile acid composition suggest different mechanisms of cholesterol stone formation in Bolivia and the United States. Gastroenterology 78: $1311,1980$. 